\title{
Ascending aortopathy with bicuspid aortic valve: Individualizing the threshold
}

\author{
Vincent R. Conti, MD, and Abe DeAnda, Jr, MD
}

\author{
From the Division of Cardiothoracic Surgery, University of Texas Medical Branch-Galveston, Galveston, Tex. \\ Disclosures: Authors have nothing to disclose with regard to commercial support. \\ Received for publication Sept 11, 2017; accepted for publication Sept 17, 2017; available ahead of print Oct 18, \\ 2017. \\ Address for reprints: Abe DeAnda, Jr, MD, Division of Cardiothoracic Surgery, UTMB-Galveston, 301 Univer- \\ sity Blvd, Galveston, TX 77755 (E-mail: abdeanda@UTMB.edu). \\ J Thorac Cardiovasc Surg 2018;155:535-6 \\ 0022-5223/\$36.00 \\ Copyright (C) 2017 by The American Association for Thoracic Surgery \\ https://doi.org/10.1016/j.jtcvs.2017.09.070
}

Surgical guidelines commonly take the form of consensus statements, evidence based and ideally easily applied to the general population. Occasionally, controversy erupts when competing expert panels disagree or submit differing recommendation classes or levels of evidence. Such was the case regarding the management of the ascending aorta (AA) in the setting of a bicuspid aortic valve (BAV) when separate guideline committees led by the American College of Cardiology and the American Heart Association differed enough that a joint guideline clarification was subsequently published. ${ }^{1}$ As noted by Ikonomidis $^{2}$ in an editorial accompanying the published clarification, part of the issue is that there is a limit in the "nature of the indices used to predict the need for operation."

Sievers and colleagues ${ }^{3}$ have previously championed the concept of a patient-specific approach to the management of the AA during intervention on the aortic valve. This approach uses a combination of AA diameter, body surface area, and age, as well as such additional factors as aortic wall frailty and family history, and incorporates the Sievers BAV classification in the analysis. Sievers and colleagues ${ }^{3}$ were able to show that this approach was useful, at least in the short term.

In this issue of the Journal, Sievers and associates ${ }^{4}$ now present us with a refinement of this approach to BAV, incorporating their experience into the creation of a $z$ score and nomograms that provide further guidance regarding whether the changes in the AA warrant aortic replacement (or repair) at the time of aortic valve replacement (AVR). They support the inclusion of multiple variables other than size alone, which has the effect of modifying the indications for intervening on the AA outside the guidelines threshold of $4.5 \mathrm{~cm}$. On the basis of their results, a lower diameter threshold could be justified in small female patients and younger patients, which intuitively makes sense. Their model also includes those with primarily aortic incompetence, or with cusp orientation causing more aortic wall shear stress (BAV type 1). Their data also clearly

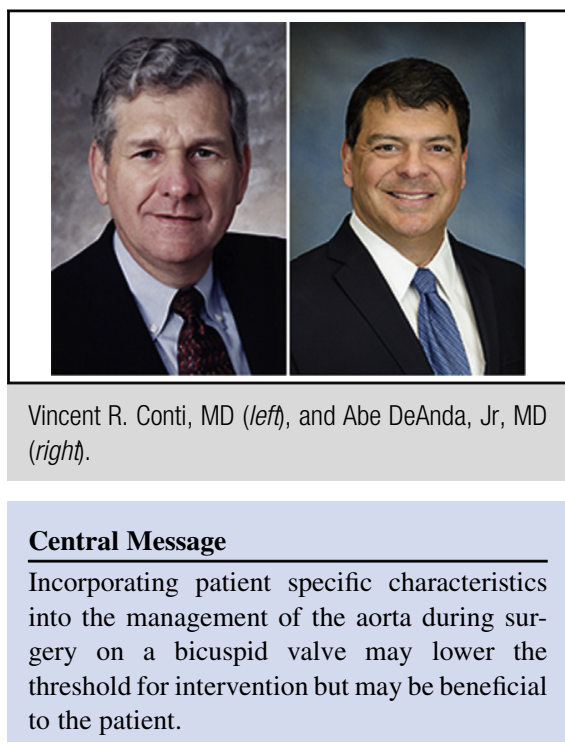

See Article page 549

support the option of AA replacement in preference to aortoplasty, which was associated with more late failures.

Multiple recent studies have attempted to address the issue raised by Ikonomidis ${ }^{2}$ and explored in this current study by Sievers and associates, ${ }^{4}$ attempting to define the critical indices that would help the surgeon decide when best to intervene on the AA when replacing a BAV. There is good evidence that structural aortic wall abnormalities, 5,6 the shear stress created by the orientation of the cusps, ${ }^{7,8}$ and the presence of primarily aortic incompetence instead of stenosis all contribute to the incidence of aortopathy with BAV. What is not clear is whether AVR alone for BAV with an AA that does not quite reach the guideline threshold for replacement will prevent further aortic dilatation with time. Studies have indicated that there are similar rates of aortic root dilatation after AVR for aortic stenosis from a tricuspid valve as with a $\mathrm{BAV},{ }^{9}$ with the possible exception of AVR for aortic incompetence caused by BAV. ${ }^{10}$

The excellent outcomes and very low risk of aortic complications seen with the new criteria of Sievers and associates $^{4}$ for addressing the AA support their use, with the hope that longer term follow-up would further clarify the indications for the combined procedure. The result may be that there will be more early interventions on aortas at smaller diameters, but if this is beneficial to the patient in the long-term, then the patient-specific approach 
championed by Sievers and associates ${ }^{4}$ should be applauded.

\section{References}

1. 2010 ACCF/AHA/AATS/ACR/ASA/SCA/SCAI/SIR/STS/SVM Guidelines for the Diagnosis and Management of Patients With Thoracic Aortic Disease Representative Members, Hiratzka LF, Creager MA, Isselbacher EM, Svensson LG, 2014 AHA/ACC Guideline for the Management of Patients With Valvular Heart Disease Representative Members, et al. Surgery for aortic dilatation in patients with bicuspid aortic valves: a statement of clarification from the American College of Cardiology/American Heart Association Task Force on Clinical Practice Guidelines. J Thorac Cardiovasc Surg. 2016;151:959-66.

2. Ikonomidis JS. Surgery for bicuspid valve aortopathy clarified-for now. $J$ Thorac Cardiovasc Surg. 2016;151:967-8.

3. Sievers HH, Stierle U, Mohamed SA, Hanke T, Richardt D, Schmidtke C, et al. Toward individualized management of the ascending aorta in bicuspid aortic valve surgery: the role of valve phenotype in 1362 patients. J Thorac Cardiovasc Surg. 2014;148:2072-80.

4. Sievers HH, Stock S, Stierle U, Klotz S, Charitos EI, Diwoky M, et al. Longerterm results, $z$ scores, and decision nomograms for treatment of the ascending aorta in 1693 bicuspid aortic valve operations. J Thorac Cardiovasc Surg. 2018;155:549-59.
5. Tsamis A, Phillippi JA, Koch RG, Chan PG, Krawiec JT, D’Amore A, et al. Extracellular matrix fiber microarchitecture is region-specific in bicuspid aortic valve-associated ascending aortopathy. J Thorac Cardiovasc Surg. 2016;151: 1718-28.e5.

6. Haunschild J, Schellinger IN, von Salisch S, Bakhtiary F, Misfeld M, Mohr FW, et al. Granular media calcinosis in the aortic walls of patients with bicuspid and tricuspid aortic valves. Ann Thorac Surg. 2017;103: 1178-85.

7. Shan Y, Li J, Wang Y, Wu B, Barker AJ, Markl M, et al. Aortic shear stress in patients with bicuspid aortic valve with stenosis and insufficiency. J Thorac Cardiovasc Surg. 2017;153:1263-72.e1.

8. Youssefi P, Gomez A, He T, Anderson L, Bunce N, Sharma R, et al. Patient-specific computational fluid dynamics - assessment of aortic hemodynamics in a spectrum of aortic valve pathologies. J Thorac Cardiovasc Surg. 2017;153: 8-20.e3.

9. Girdauskas E, Disha K, Borger MA, Kuntze T. Long-term prognosis of ascending aortic aneurysm after aortic valve replacement for bicuspid versus tricuspid aortic valve stenosis. J Thorac Cardiovasc Surg. 2014; 147:276-82.

10. Wang Y, Wu B, Li J, Dong L, Wang C, Shu X. Impact of aortic insufficiency on ascending aortic dilatation and adverse aortic events after isolated aortic valve replacement in patients with a bicuspid aortic valve. Ann Thorac Surg. 2016; 101:1707-14. 